\title{
SOBREVIVÊNCIA DE ESPECIES MADEIRÁVEIS EM SISTEMA AGROSSILVIPASTORIL EM SÃO DOMINGOS DO ARAGUAIA, PA
}

\author{
Albinei Araujo de Castro'; Rosana Quaresma Maneschy² ; Ilmaione Keiza de Souza Oliveira; \\ Tatiane Pereira Guimarães ${ }^{4}$; Karolinny Carneiro Guerra Costa 5 . \\ ${ }^{1}$ Discente de Agronomia da UFPA - Campus de Marabá, Bolsista FAPESPA, albinei_araujo@ @otmail.com \\ ${ }^{2}$ Prof. a, DSc., FCAM, UFPA, romaneschy@ufpa.br \\ ${ }^{3}$ Discente de Agronomia da UFPA - Campus de Marabá, Bolsista PIBIC/PARD, ilmaionekeiza@ hotmail.com \\ ${ }^{4}$ Discente de Agronomia da UFPA - Campus de Marabá, Bolsista FAPESPA, tatianepg.ufpa@gmail.com \\ ${ }^{5}$ Discente de Agronomia da UFPA - Campus de Marabá, Bolsista PIBIC/UFPA, karolinnycg.guerra@gmail.com
}

\begin{abstract}
RESUMO: Os sistemas agrossilvipastoris têm sido uma alternativa indicada para reabilitação de áreas de pastagens degradadas. Objetivou-se avaliar a taxa de sobrevivência de mudas de espécies madeiráveis em ação-teste agrossilvipastoril implantada em unidade de produção familiar no assentamento "Belo Horizonte I", em São Domingos do Araguaia-PA. Foram avaliadas durante um ano as espécies: ipê amarelo (Tabebuia serratifolia), ipê branco (T. roseo-alba), ipê roxo (Tabebuia cf. impetiginosa), oiti (Moquilea tomentosa), paricá (Schizolobium parahyba var. amazonicum), pata de vaca (Bauhinia longifolia), sapucaia (Lecythis pisonis) e sombreiro (Clitorea racemosa). As taxas de sobrevivência das espécies ipê amarelo, ipê branco, ipê roxo, paricá, oiti e sapucaia foram considerados satisfatórias sob as condições disponíveis da unidade de produção familiar estudada.
\end{abstract}

PALAVRAS-CHAVES: agricultura familiar, sistema agroflorestal, taxa de sobrevivência.

\section{SURVIVAL IN SYSTEM TIMBER SPECIES AGROSYLVOPASTORAL IN SANTO DOMINGO DO ARAGUAIA, PA}

\begin{abstract}
The silvopastoral system has been given an alternative for rehabilitation of degraded pastures. The objective was to evaluate the survival rate of seedlings of timber species in action-test agrosilvopasture deployed in family production unit in the settlement "Belo Horizonte I", São Domingos do Araguaia-PA. Were measured for one year the following species: Tabebuia serratifolia, T. roseo-alba, Tabebuia cf. impetiginosa, Moquilea tomentosa, Schizolobium parahyba var. amazonicum, Bauhinia longifolia, Lecythis pisonis and Clitoria racemosa. The survival rates of species $T$. serratifolia, $T$. roseo-alba, $T$. cf. impetiginosa, $S$. parahyba, $M$. tormentosa and $L$. pisonis were considered satisfactory under the conditions available from family production unit studied.
\end{abstract}

KEY-WORDS: agroforestry system, family farm, survival rate.

Estima-se que cerca da metade das áreas de pastagens formadas na Amazônia esteja degradada ou em processo de degradação, devido à atividade pecuária praticada por pequenos agricultores familiares estarem associada ao desmatamento e a utilização de baixo insumo tecnológico (DIAS-FILHO,
2003). Como alternativa para reabilitação dessas áreas, os sistemas agrossilvipastoris tem sido uma alternativa indicada, pois propiciam efeitos benéficos sobre animais, pastagem, solo, conservação dos recursos hídricos e aumento da biodiversidade. Esses sistemas agroflorestais (SAF) associam os 
tradicionais componentes pecuários (pastagem e animal) com árvores e culturas anuais (PEZO; IBRAHIM, 1999).

A escolha de árvores apropriadas para o estabelecimento deste sistema é fundamental para se obter bom rendimento de sobrevivência das espécies. Segundo Melo e Zoby (2004) as espécies devem possuir algumas características desejáveis para utilização nesse sistema, como compatibilidade ecológica e adaptabilidade ao local, apresentar crescimento rápido e possuir troncos altos e copa pouco densa.

Apesar de no Estado do Pará já terem sido identificados SAF pecuários com $\mathrm{o}$ componente arbóreo tendo como finalidade principal a produção de madeira (VEIGA et al., 2000), utilizados principalmente por médios e grandes produtores (MANESCHY; SANTANA; VEIGA, 2009) ainda existem poucas informações sobre o desenvolvimento de espécies madeireiras sob as condições de implantação e manejo próprios dessas unidades de produção, complexas e diversificadas. Portanto, objetivou-se avaliar a taxa de sobrevivência das espécies madeiráveis em uma ação-teste agrossilvipastoril implantada em lote de agricultor familiar.

Este estudo foi uma ação do projeto "Sistemas silvipastoris e agrossilvipastoris como alternativa para a sustentabilidade da pecuária na agricultura familiar da região de Marabá - PA" desenvolvido pela Universidade Federal do Pará - Campus de
Marabá com apoio financeiro da FAPESPA. A pesquisa se desenvolveu no Projeto de Assentamento (P.A.) Belo Horizonte I, situado à altura do km 30 da BR-153, no município de São Domingos do Araguaia, na microrregião de Marabá, composto por aproximadamente 40 famílias. O clima no local segundo a classificação de Köppen é Am no limite de transição para Aw com temperatura média anual de $26,3^{\circ} \mathrm{C}$. Solo podzólico vermelho amarelo com textura argilo-arenosa.

A abordagem metodológica utilizada foi da pesquisa-ação e participativa que visa à construção de inovações em parcerias com agricultores (CHIA; DUGUÉ; SAKHOJIMBIRA, 2006). Nesse contexto foi implantada uma ação-teste agrossilvipastoril azonal, com local, quantidade de mudas e espécies escolhidas pela família. A área escolhida pelo agricultor tinha como vegetação dominante floresta primária, que foi derrubada há 15 anos para formação de pastagem com braquiarão (Brachiaria brizantha cv. marandu Hochst. ex A. Rich), sendo pastejado por 10 anos e deixado em repouso durante os últimos cinco anos.

As espécies escolhidas pela família para a ação-teste agrossilvipastoril foram: graviola (Annona muricata L.), goiaba (Psidium guajava L.), oiti (Moquilea tomentosa Benth), teca (Tectona grandis L. F.), pau preto (Dalbergia nigra (Vell.) Fr.All. ex Benth), jatobá (Hymenaea courbaril L.), ipê roxo (Tabebuia cf. impetiginosa (Mart. exDC.) 
Standl), ipê amarelo (Tabebuia serratifolia Valh), ipê branco (Tabebuia roseo-alba Ridl.), ipê rosa (Tabebuia heptaphylla (Vell.) Toledo), pata de vaca (Bauhinia longifolia (Bong.) Steud.), neem (Azadirachta indica A. Juss.), aroeira (Schinus terebinthifolius Raddi.), sapucaia (Lecythis pisonis Cambess.), paricá (Schizolobium parahyba var. amazonicum (Huber ex Ducke) Barneby) e o sombreiro (Clitorea racemosa Sessé \& Moc.). Após 15 dias da implantação destas espécies o agricultor plantou entre as linhas a cultura da mandioca (Manihot esculenta Crantz) e do arroz (Oryza sativa L.), realizando capina regularmente.

Para a implantação da ação-teste foi implantada em solo com as seguintes características: Areia grossa $=191 \mathrm{~g} \mathrm{~kg}^{-1}$; Areia fina $=434 \mathrm{~g} \mathrm{~kg}^{-1} ;$ Silte $=206 \mathrm{~g} \mathrm{~kg}^{-1} ; \mathrm{pH}$ $=5,8 ; \mathrm{P}=6 \mathrm{mg} \mathrm{dm}^{-3} ; \mathrm{K}=163 \mathrm{mg} \mathrm{dm}^{-3} ; \mathrm{Na}=$ $62 \mathrm{mg} \mathrm{dm}^{-3} ; \mathrm{Ca}=2,8 \mathrm{cmol}_{\mathrm{c}} \mathrm{dm}^{-3} ; \mathrm{Ca}+\mathrm{Mg}=$ $3,8 \mathrm{cmol}_{\mathrm{c}} \mathrm{dm}^{-3}$; e $\mathrm{Al}=0,1 \mathrm{cmol}_{\mathrm{c}} \mathrm{dm}^{-3}$. O preparo da área utilizou mecanização, realizando o processo de aração e gradagem, para limpeza da mesma. A ação-teste foi implantada em fevereiro de 2010, em uma área de $3720 \mathrm{~m}^{2}$. As mudas das espécies implantadas foram plantadas em fileiras aleatoriamente. $\mathrm{O}$ espaçamento utilizado entre as linhas foi de $10 \mathrm{~m}$, e entre as plantas na linha foi de $4 \mathrm{~m}$.

Para a avaliação das espécies madeiráveis, foram desconsideradas as espécies que se encontravam nas fileiras externas, devido o efeito bordadura. As avaliações foram realizadas em oito espécies (ipê amarelo, ipê branco, ipê roxo, oiti, paricá, pata de vaca, sapucaia e sombreiro) com igual ou superior a três indivíduos, sendo elas: taxa de sobrevivência de março de 2010 a março de 2011. Na ocasião da avaliação também era realizada uma entrevista com os membros da família responsáveis pela ação a fim de levantar os tratos culturais realizados mensalmente.

Ressalta-se que para a implantação e manutenção da ação-teste não houve adubação química e/ou orgânica. Sendo realizada apenas uma limpeza a fim de diminuir a competição das espécies estudadas com as invasoras. Isso pode ter prejudicado o sombreiro e a pata de vaca, espécies em que a taxa de sobrevivência foi inferior a $50 \%$ (Tabela 1). A taxa de sobrevivência dos ipês, espécies da família Bignoniaceae, pode ser explicada pelo teor de nutrientes e acidez do solo onde foi implantada a ação-teste, pois de acordo com Carvalho (1994) solos com fertilidade química de média a elevada, profundos, com boa drenagem e de textura franca a argilosa são favoráveis ao desenvolvimento e sobrevivência destas espécies. Segundo Franke (1999) essas espécies podem ser utilizadas como cerca viva, mourão, madeira comercial, madeira nobre e sombra. 
Tabela 1. Avaliação da taxa de sobrevivência das espécies madeiráveis em sistema agrossilvipastoril no P. A. Belo Horizonte I, São Domingos do Araguaia - PA.

\begin{tabular}{|c|c|c|c|c|c|c|c|c|c|c|c|c|c|c|c|}
\hline \multirow{2}{*}{ FAMÍLIA } & \multirow{2}{*}{ Espécie } & \multirow{2}{*}{$\mathrm{N}$} & \multicolumn{10}{|c|}{2010} & \multicolumn{3}{|c|}{2011} \\
\hline & & & $\operatorname{mar}$ & $\mathrm{abr}$ & mai & jun & jul & ago & set & out & nov & $\operatorname{dez}$ & jan & fev & $\operatorname{mar}$ \\
\hline \multicolumn{16}{|c|}{ BIGNONIACE AE } \\
\hline & IAM & 10 & 70 & 70 & 70 & 70 & 70 & 70 & 70 & 70 & 70 & 70 & 70 & 70 & 70 \\
\hline & IBR & 16 & 93 & 93 & 93 & 93 & 93 & 93 & 93 & 93 & 87 & 87 & 87 & 87 & 87 \\
\hline & IRX & 4 & 100 & 100 & 100 & 100 & 100 & 100 & 75 & 75 & 75 & 75 & 75 & 75 & 75 \\
\hline \multicolumn{16}{|c|}{ FABACEAE } \\
\hline & PRC & 9 & 100 & 100 & 100 & 100 & 100 & 100 & 100 & 100 & 100 & 100 & 100 & 100 & 100 \\
\hline & PTV & 7 & 71 & 71 & 57 & 57 & 57 & 57 & 57 & 57 & 42 & 42 & 42 & 42 & 42 \\
\hline & SBR & 22 & 36 & 36 & 36 & 36 & 36 & 36 & 36 & 36 & 36 & 36 & 36 & 36 & 36 \\
\hline \multicolumn{16}{|c|}{ CHRYSOBALANACEAE } \\
\hline & OIT & 3 & 100 & 100 & 66 & 66 & 66 & 66 & 66 & 66 & 66 & 66 & 66 & 66 & 66 \\
\hline \multicolumn{16}{|c|}{ LECYTHIDACEAE } \\
\hline & SAP & 3 & 66 & 66 & 66 & 66 & 66 & 66 & 66 & 66 & 66 & 66 & 66 & 66 & 66 \\
\hline
\end{tabular}

Onde: IAM = ipê amarelo, IBR = Ipê branco, IRX = Ipê roxo, PRC = paricá, PTV = pata de vaca, SBR = sombreiro, OIT $=$ oiti, SAP $=$ sapucaia.

Pesquisa realizada em Barcarena-Pa por Ribeiro (1998) com paricá em sistemas agroflorestais apontou índice de sobrevivência de $100 \%$ com 36 meses de idade, mesmo índice apontado neste trabalho. Esta elevada taxa de sobrevivência pode ser explicada por ser uma espécie adaptada e resistente as condições edafoclimáticas da região, pois segundo Costa (1998) o paricá é indicado para plantios em SAF e reflorestamento de áreas degradadas, devido ao seu rápido crescimento e ao bom desempenho em condições extremas, tanto em formações homogêneas quanto em consórcios, sendo que sua madeira está sendo muito utilizada para fabricação de laminados.

Os estudos com as espécies oiti e sapucaia ainda são incipientes na região, contudo, Franke (1999) afirma as mesmas podem ser utilizadas para recuperação de áreas degradadas com potencial madeireiro, se prestando para ser utilizada na confecção de artesanato, mourão e sombra. Em relação às espécies sombreiro e pata de vaca, esse baixo índice de sobrevivência pode ser explicado por Ferreira et al. (1977) que afirma que é dada pouca atenção ao conhecimento de suas exigências ecológicas, afetando seu desenvolvimento.

As taxas de sobrevivências do ipê amarelo, ipê branco, ipê roxo, paricá, oiti e sapucaia foram considerados satisfatórios na ação-teste agrossilvipastoril sob as condições disponíveis da unidade de produção familiar estudada. São espécies que possuem potencial para serem utilizadas em sistemas agroflorestais e para recuperação de áreas de 
pastagens degradadas, podendo maximizar e diversificar a produção familiar.

\section{REFERÊNCIAS}

CHIA, E.; DUGUÉ, P.; SAKHO-JIMBIRA, S. Les exploitations agricoles familiales sontelles des institutions? Agricultures, v. 15, n. 6, p. 498-505, 2006.

COSTA, D. H. M.; REBELlO, F. K.; D’ÁVILA, J. L.; SANTOS, M. A. S.; LOPES, M. L. B. Alguns aspectos silviculturais sobre o paricá (Schizolobium amazonicum Huber). Belém, BASA. 1998. 19p.

DIAS-FILHO, M. B. Degradação de pastagens: processos, causas e estratégias de recuperação. Belém: Embrapa Amazônia Oriental, 2003. 152 p.

FERREIRA, M. G. M.; CANDIDO, J. F.; CANO, M. A. O.; CONDE, A. R. Efeito do sombreamento na produção de mudas de quatro espécies florestais nativas. Revista Árvore, v.1, n.2, p.121-134, 1977.

MANESCHY, R. Q.; SANTANA, A. C.; VEIGA, J. B. Viabilidade Econômica de Sistemas Silvipastoris com Schizolobium parahyba var. amazonicum e Tectona grandis no Pará. Pesquisa Florestal Brasileira, n. 60, p. 49-56, 2009.

MELO, J. T.; ZOBY, J. L. F. Espécies para arborização de pastagens. Planaltina: Embrapa-CPAC, 2004. 4p. (Circular Técnica, 113).
FRANKE, I. L. Principais usos e serviços de árvores $\mathrm{e}$ arbustos promissores que ocorrem em pastagens no Estado do Acre. Rio Branco: Embrapa Acre, 1999. 6 p.

PEZO, D.; IBRAHIM, M. Sistemas Silvopastoriles. Turrialba, Costa Rica: CATIE, 1999. 276 p.

VEIGA, J. B.; PEREIRA, C. A.; MARQUES, L. C. T.; VEIGA, D. F. Sistemas Silvipastoris na Amazônia Oriental. Belém: Embrapa Amazônia Oriental, 2000. 62 p.

RIBEIRO, G. D. Avaliação preliminar de sistemas agroflorestais no Projeto Água Verde, ALBRÁS, Barcarena, PA. Belém, 1997. 100 p. Dissertação (Mestrado em Ciências Florestais) - Faculdade de Ciências Agrárias do Pará. 1997. 